\title{
Socioeconomic, demographic, and obstetric inequalities in food insecurity in pregnant women
}

\author{
Renata Cordeiro Fernandes 1 \\ Fernanda Manera 2 \\ Larissa Boing 3 \\ Doroteia Aparecida Höfelmann 4
}

\footnotetext{
1,2 Programa de Pós Graduação em Alimentação e Nutrição. Universidade Federal do Paraná. Av. Prefeito. Lothário Meisser, 632. Jardim Botânico. Curitiba, PR, Brasil. CEP: 80.060-000. E-mail: renatacordeirofernandes@gmail.com

3 Residência Multiprofissional em Saúde da Família. Universidade Federal do Paraná. Curitiba, PR, Brasil.

4 Departamento de Nutrição. Universidade Federal do Paraná. Curitiba, PR, Brasil.
}

\begin{abstract}
Objectives: to estimate the prevalence of Food Insecurity (FI) in pregnant women and to identify its association with demographic, socioeconomic, obstetric, and anthropometric variables in female users of Family Health Units (FHUs) in the city of Colombo, state of Paraná, South Region of Brazil.

Methods: a cross-sectional study of a representative sample of pregnant women from 17 FHUs in Colombo. We used the short version of the Brazilian Household Food Insecurity Measurement Scale (EBIA). In addition, we used Poisson Regression Models with robust, crude, and adjusted variance to investigate the association between FI and exposure variables.

Results: 316 pregnant women participated in the study. The prevalence of FI was $45.1 \%$ $(C 195 \%=39.6-50.6)$. Adjusted analysis showed higher prevalence of FI in pregnant women with 30 years of age or older $(P R=1.66 ; I C 95 \%=1.02-2.69)$, with black skin or indigenous background $(P R=1.39 ; C I 95 \%=1.08-1.79)$, with 7 years of education or less $(P R=1.58$; $C I 95 \%=1.14-2.19)$, and with lower income $(P R=2.07 ; C 195 \%=1.36-3.14)$.

Conclusions: There was a high prevalence of FI among pregnant women, particularly among those of older age and with worse socioeconomic conditions, a group that should be considered a priority for actions aimed at promoting food security.
\end{abstract}

Key words Food security, Pregnancy, Social inequality, Cross-sectional studies 


\section{Introduction}

Food is one of the most basic requirements for human life. ${ }^{1}$ Food insecurity (FI) occurs when one or more residents of a household are apprehensive about the unavailability of food or when there is a break in eating patterns, reducing the quantity or quality of food. ${ }^{2}$ That is, FI is the uncertainty of being free from hunger. ${ }^{3}$ It is characterized by fears regarding access to food due to physical, social, or economic issues. Hunger may be present in severe FI cases. 4,5

The main factors that influence FI are low per capita income, low education, high number of residents per household (or, on the other hand, the fact that the individual lives alone), high food costs, poor sanitation, and unemployment.6-8 It was estimated that, in 2013, 52 million (22.6\%) Brazilians were facing FI; of these, 4.78 million $(9.2 \%)$ were residents of the South Region. 5

In Brazil, the prevalence of FI has been investigated in different population groups, such as the elderly, small farmers, the unemployed, children, and women. ${ }^{1}$ Studies conducted in recent years show that, among these groups, pregnant women have a prevalence of FI ranging from $37.8 \% 9$ to $42.7 \% .10$ During pregnancy, increased energy needs, as well as macro and micronutrients, make FI an issue of even greater concern, since it may compromise the development of fetal organs and systems, as well as their chances of survival after birth. 11

FI has also been considered a risk factor for the pregnant woman's health: there is evidence associating FI with the impairment of her nutritional status, higher blood pressure levels, hyperglycemia, higher prevalence of anemia, and repercussions on the mental health of both mother and fetus. ${ }^{9-11}$

Considering the negative effects of FI on pregnancy outcome, it is essential to elucidate the factors that contribute to its prevalence in certain social groups. The study of these conditions in places frequented by pregnant women, such as health units and maternity hospitals, can improve the understanding of this problem.

In light of these issues, the purpose of the present study was to estimate the prevalence of FI in pregnant women and to identify its association with demographic, socioeconomic, obstetric, and anthropometric variables in users of Family Health Units (FHU).

\section{Methods}

This research consisted of a cross-sectional study, conducted with pregnant women who underwent prenatal care at Family Health Units (FHUs) in the city of Colombo, Paraná, between April and November 2016.

Colombo is part of the Metropolitan Region of Curitiba and had an estimated population of 234,941 inhabitants in 2016.12 In 2010, the city presented a Human Development Index of 0.73, a Gini Index of 0.41 , life expectancy at birth of 77.17 years, infant mortality rate of 10.64 per 1,000 live births, and maternal mortality ratio of 51.89 deaths per 100,000 births. ${ }^{12}$

At the beginning of data collection (May 2016), Colombo's primary health care system consisted of 17 FHUs, and, according to information from the Municipal Health Department's Women's Health Program, 1,375 pregnant women were under prenatal care in the city.

To define sample size, we considered the prevalence of the outcome of $50 \%$ (to maximize the sample size), a margin of error of $5 \%$, and a confidence level of $95 \%$. This enabled the obtention of a sample consisting of 301 pregnant women. Considering a rate of $20 \%$ of loss due to refusals, the expected amount was increased in $20 \%$, totaling a sample of 361 pregnant women. Sampling size calculations were performed using the 3.01 version of the OpenEpi online application.

Estimates for the analyses of association were calculated a posteriori, based on the number of observations of the variable with the lowest response rate (income, $n=282$ ). With a confidence level of $95 \%$ and power of $80 \%$, they made it possible to identify associations between outcome (IA) and exposures with a minimum prevalence ratio (PR) of 1.18 , considering a prevalence of $45.1 \%$ in the nonexposed group and $53.4 \%$ in the exposed group.

The team of interviewers was composed of nine members, which were nutritionists and nutrition undergraduate students linked to the Federal University of Paraná (UFPR). Data consisted of a semi-structured, pre-coded, tested questionnaire. In the month directly before the beginning of data collection, a pre-test of the questionnaire was conducted to assess the duration of the interview and the comprehensibility of the questions. This pre-test took place in one of the FHUs, and participants of this phase were not included in the final sample.

The researchers contacted all FHUs to check the days and times of prenatal appointments and scheduled the interviewers' visits accordingly. Pregnant women scheduled for prenatal care were invited until the expected number of participants for each unit was reached. The inclusion criterion was to be at any 
gestational age and of any skin color, and to be at the age of 18 or above. The exclusion criterion was any physical or intellectual incapacity that prevented participation in the study. The pregnant women were invited to participate in the study while waiting for their prenatal appointments to start.

The sample distribution was proportional to the number of pregnant women registered in each FHU. The interviews took place in the waiting room for the appointments. FHU employees measured the pregnant women's body weight using mechanical scales calibrated during pre-consultation.

The questionnaire was designed to cover demographic, socioeconomic, obstetric, and nutritional variables. The demographic variables were age range (in years, 0-19, 20-29, 30 or more), self-reported skin color/race (white and yellow or black, brown and indigenous. Hereafter, yellow people will be referred to as "Asian;" black- and brown-colored people will be grouped within the general category "black"), and marital status (with partner vs. without partner). The socioeconomic variables were: per capita household income (in Brazilian Real, classified in terciles: 1 st tercile from $\mathrm{R} \$ 18.70$ to $\mathrm{R} \$ 399$; $2^{\text {nd }}$ tercile from $\mathrm{R} \$ 400$ to $\mathrm{R} \$ 749 ; 3$ rd tercile from $\mathrm{R} \$ 750$ to $\mathrm{R} \$ 5,000$, with the monthly minimum salary at the time of data collection being R $\$ 880$ (In US dollars, classified in terciles: 1 st tercile US\$ 5.74-122.44; 2nd tercile US\$ 122.74-229.84; 3 rd tercile US\$ 230.15-1,534.30. Quotation: 12/31/2016, Central Bank of Brazil, R\$ 3.2588), schooling (in years, $0-7,8-10,11$ or more), beneficiary of the Bolsa Familia Program, a conditional cash transfer program (no vs. yes), and paid work (no vs. yes). In relation to the obstetric background, we considered the number of pregnancies (one, two, three, or more). The nutritional status of the participants was assessed based on their weight and height, with posterior measurement of body mass index and its classification (underweight, normal weight, overweight, or obesity) according to the gestational week at the time of assessment. ${ }^{13}$

FI was determined using the short version of the Brazilian Household Food Insecurity Measurement Scale (EBIA), proposed by Santos et al., 14 validated in Campinas 15 and derived from the American food insecurity measurement scale proposed by Bickel et $a l .{ }^{2}$ The short version of EBIA was compared in two different scenarios: 1) low-income families from the city of Pelotas, in the southern Brazilian state of Rio Grande do Sul ( $\mathrm{n}=230)$, and 2) women from the Brazil National Demographic and Health Survey (PNDS, 2006) $(n=15,575)$. The analyses of the fivequestion version indicated sensitivity of $95.7 \%$ and
99.5\% in the Pelotas and PNDS samples, respectively, and agreement of $95.0 \%$ and $99.0 \%$, also respectively. The short version is composed of five questions and allows to classify FI dichotomously (presence vs. absence). In this way, pregnant women who answered "yes" to at least one of the five questions were considered to be in a state of FI. 14

For the descriptive analysis of categorical variables, we calculated absolute (n) and relative (\%) frequencies. Crude and adjusted prevalence ratios (PR) and corresponding confidence intervals of $95 \%$ (IC95\%) were calculated using Poisson regression with robust variance and using the Wald test for calculation of $p$ values. The entry order of variables in the adjusted analyses followed the hierarchical model, with demographic variables being inserted first, followed by socioeconomic, obstetric, and anthropometric variables. The variables with a $p$ value up to 0.25 in the crude analysis were inserted in the adjusted analyses and were considered statistically significant when showing a $p$ value $<0.05$. The analyses were carried out in the Stata 12 software. 16

This study was conducted within the required ethical standards and approved by the Human Research Ethics Committee of UFPR (opinion number: 1463691). The pregnant women were verbally invited to participate in the study and made aware of its goals. Only those who read and signed the Free, Prior, and Informed Consent form (FPIC) participated in the study.

\section{Results}

322 pregnant women were considered eligible. Six $(1.9 \%)$ of them did not agree to participate in the study, resulting in a final sample of 316 women. Age ranged from 18.0 to 45.7 years, an average of 26.2 years ( standard deviation $=6.0$ ).

Most of women had a partner (83.5\%), identified themselves as having black or indigenous skin color/race $(50.5 \%)$, and were not beneficiaries of the Bolsa Família Program (86.1\%). 38.9\% of the participants had eight to 10 years of education; $34.0 \%$ had per capita income between $\mathrm{R} \$ 400$ and $\mathrm{R} \$ 749$ (US\$ 122.74-229.84, 2nd tercile); and 33.9\% had gone through three or more pregnancies. Regarding nutritional status, $46.2 \%$ of the participants were considered overweight or obese considering the gestational week (Table 1).

The prevalence of FI among pregnant women was $45.1 \%$ (CI95\%, 39.6-50.6\%) (Table 1). Among the pregnant women with FI, the item with the most positive responses was related to their preoccupation that food would end before they were able to 
Distribution of pregnant women according to demographic, socioeconomic and obstetric background variables and to the Brazilian Household Food Insecurity Measurement Scale. Colombo, Paraná, 2016. ( $N=316)$

\begin{tabular}{|c|c|c|}
\hline Variables & $\mathbf{N}$ & $\%$ \\
\hline \multicolumn{3}{|l|}{ Demographic } \\
\hline \multicolumn{3}{|l|}{ Age range (in years) } \\
\hline $0-19$ & 45 & 14.2 \\
\hline $20-29$ & 189 & 59.8 \\
\hline 30 or more & 82 & 26.0 \\
\hline \multicolumn{3}{|l|}{ Marital status } \\
\hline With partner & 264 & 83.5 \\
\hline Without a partner & 52 & 16.5 \\
\hline \multicolumn{3}{|l|}{ Color/race } \\
\hline White and Asian & 156 & 49.5 \\
\hline Black and indigenous & 159 & 50.5 \\
\hline \multicolumn{3}{|l|}{ Socioeconomic } \\
\hline \multicolumn{3}{|l|}{ Paid Work } \\
\hline Yes & 138 & 43.7 \\
\hline No & 178 & 56.3 \\
\hline \multicolumn{3}{|l|}{ Bolsa Família Program } \\
\hline No & 272 & 86.1 \\
\hline Yes & 44 & 13.9 \\
\hline \multicolumn{3}{|l|}{ Schooling (in years) } \\
\hline $0-7$ & 74 & 23.4 \\
\hline $8-10$ & 123 & 38.9 \\
\hline 11 or more & 119 & 37.7 \\
\hline \multicolumn{3}{|c|}{ Household income per capita (in reais) } \\
\hline $18.70-399$ & 94 & 33.3 \\
\hline $400-749$ & 96 & 34.0 \\
\hline $750-5000$ & 92 & 32.7 \\
\hline \multicolumn{3}{|l|}{ Obstetric } \\
\hline \multicolumn{3}{|l|}{ No. of pregnancies } \\
\hline One & 96 & 30.4 \\
\hline Two & 113 & 35.7 \\
\hline Three or more & 107 & 33.9 \\
\hline \multicolumn{3}{|c|}{ Nutritional status during pregnancy } \\
\hline Low weight & 37 & 12.2 \\
\hline Eutrophy & 126 & 41.6 \\
\hline Overweight & 93 & 30.7 \\
\hline Obesity & 47 & 15.5 \\
\hline \multicolumn{3}{|l|}{ Food Insecurity } \\
\hline Yes & 142 & 45.1 \\
\hline No & 173 & 54.9 \\
\hline
\end{tabular}

Quantity of information ignored by the variable: age $n=1$; color/race, $n=4$; paid work $n=1$; Bolsa Familia Program $n=1$; schooling $n=1$, household income per capita $n=34$; number of pregnancies $n=1$; nutritional status $n=13$; food insecurity, $\mathrm{n}=1$. Household income per capita in US Dollars: 1 st tercile $\$ 5.74-122.44 ; 2$ nd tercile $\$ 122.4-229.84$; 3rd tercile $\$ 230.15-1534.30$ (quote held on 12/31/2016 by the Central Bank of Brazil R\$3.2588) 
purchase, receive, or produce more food $(73.2 \%)$, followed by the item concerning being ran out of food before they were able to purchase, receive, or produce more food (31.7\%) (Table 2).

In the unadjusted analyses, there was a higher prevalence of FI among women aged 30 years or older $(\mathrm{PR}=1.72, \mathrm{CI} 95 \%=1.06-2.78)$, with black skin color/indigenous race $(\mathrm{PR}=1.41, \mathrm{CI} 95 \%=1.09$ $1.81)$, without paid work $(\mathrm{PR}=1.47, \mathrm{CI} 95 \%=1.13$ 1.92), receiving Bolsa Família $(\mathrm{PR}=1.58, \mathrm{CI} 95 \%=$ $1.22-2.04)$, with 0 to 7 years of education $(\mathrm{PR}=1.84$, $\mathrm{CI} 95 \%=1.33-2.55)$, from the 1 st tercile of income $(\mathrm{PR}=2.59, \mathrm{CI} 95 \%=1.76-3.81)$, and with three or more pregnancies $(\mathrm{PR}=2.03, \mathrm{CI} 95 \%=1.43-2.89)$ (Table 3).

After the adjusted analysis, the association of FI with the 30 years or older age group $(P R=1.66$,
$\mathrm{CI} 95 \%=1.02-2.69)$ and with women of black skin color/indigenous race $(\mathrm{PR}=1.39 ; \mathrm{CI} 95 \%=1.08$ 1.79) remained statistically significant. Among pregnant women with up to seven years of education, the prevalence of FI was $1.58(\mathrm{CI} 95 \%=1.14-2.19)$ higher than those with 11 years or more, after adjusting for demographic and socioeconomic variables. Among pregnant women with lower per capita income ( 1 st tercile), the prevalence of FI was 2.07 $(\mathrm{CI} 95 \%=1.36-3.14)$ higher than those with higher income, after adjusting for demographic and socioeconomic variables. The association with variables related to marital situation, paid work, Bolsa Família Program, and number of pregnancies was no longer statistically significant after adjustment for the demographic and socioeconomic variables investigated (Table 3).

\section{Table 2}

Distribution of pregnant women who answered "yes" to the questions from the short version of the Brazilian $\mathrm{Fl}$ Measurement Scale. Colombo, Paraná, 2016.

\begin{tabular}{|c|c|c|c|}
\hline \multirow{2}{*}{ Item } & \multirow{2}{*}{ Question } & \multicolumn{2}{|c|}{ With FI } \\
\hline & & $n$ & $\%$ \\
\hline 1 & $\begin{array}{l}\text { In the last three months, did you have the preoccupation that } \\
\text { the food in your house would end before you were able to } \\
\text { purchase, receive or produce more food? }\end{array}$ & 104 & 73.2 \\
\hline 2 & $\begin{array}{l}\text { In the last three months, did the food end before you had } \\
\text { money to buy more? }\end{array}$ & 45 & 31.7 \\
\hline 3 & $\begin{array}{l}\text { In the last three months, did you run out of money in order to } \\
\text { have healthy and varied meals? }\end{array}$ & 92 & 64.8 \\
\hline 4 & $\begin{array}{l}\text { In the last three months, did you or any adult in your home } \\
\text { decrease, from time to time, the amount of food at meals or } \\
\text { did you skip meals because there was not enough money to } \\
\text { buy food? }\end{array}$ & 29 & 20.4 \\
\hline 5 & $\begin{array}{l}\text { In the last three months, did you eat less than necessary } \\
\text { because there was not enough money to buy food? }\end{array}$ & 25 & 17.6 \\
\hline
\end{tabular}

Quantity of information ignored by the variable: Item $1 \mathrm{n}=1$. 
Prevalence of food insecurity according to demographic and socioeconomic characteristics, obstetric and anthropometric background of pregnant women in Family Health Unities (FHU). Colombo, Paraná, 2016. $(n=316)$

\begin{tabular}{|c|c|c|c|c|c|c|}
\hline \multirow[t]{2}{*}{ Variables } & \multicolumn{2}{|c|}{$\mathrm{Fl}^{*}$} & \multirow[t]{2}{*}{ PR gross (C195\%) } & \multirow[t]{2}{*}{$p^{* *}$} & \multirow[t]{2}{*}{ Adjusted PR (Cl95\%) } & \multirow[t]{2}{*}{$p^{* *}$} \\
\hline & $\mathrm{n}$ & $\%$ & & & & \\
\hline \multicolumn{7}{|l|}{ Demographic } \\
\hline Age range (in years) & & & & 0.015 & & $0.023 a$ \\
\hline $0-19$ & 14 & 31.1 & 1.00 & & 1.00 & \\
\hline $20-29$ & 84 & 44.7 & $1.43(0.90-2.28)$ & & $1.41(0.88-2.23)$ & \\
\hline 30 or more & 44 & 53.7 & $1.72(1.06-2.78)$ & & $1.66(1.02-2.69)$ & \\
\hline Marital status & & & & 0.255 & & - \\
\hline With partner & 115 & 43.7 & 1.00 & & - & \\
\hline Without a partner & 27 & 57.9 & $1.18(0.88-1.59)$ & & - & \\
\hline Color/race & & & & 0.007 & & $0.009 a$ \\
\hline White and Asian & & 36.7 & 1.00 & & 1.00 & \\
\hline Black and indigenous & 62 & 54.2 & $1.41(1.09-1.81)$ & & $1.39(1.08-1.79)$ & \\
\hline Socioeconomic & 77 & & & & & \\
\hline Paid Work & & & & 0.004 & & - \\
\hline Yes & 49 & 35.5 & 1.00 & & - & \\
\hline No & 93 & 52.5 & $1.47(1.13-1.92)$ & & - & \\
\hline Bolsa Familia Program & & & & $<0.001$ & & $0.121 b$ \\
\hline Yes & 113 & 41.7 & 1.00 & & 1.00 & \\
\hline No & 29 & 65.9 & $1.58(1.22-2.04)$ & & $1.20(0.95-1.53)$ & \\
\hline Schooling (in years) & & & & $<0.001$ & & $0.003^{b}$ \\
\hline $0-7$ & 44 & 59.5 & $1.84(1.33-2.55)$ & & $1.58(1.14-2.19)$ & \\
\hline $8-10$ & 60 & 48.8 & $1.51(1.10-2.08)$ & & $1.25(0.88-1.77)$ & \\
\hline 11 or more & 38 & 32.2 & 1.00 & & 1.00 & \\
\hline Household income per capita (in reais)*** & & & & $<0.001$ & & $<0.001 \mathrm{~b}$ \\
\hline 1st tercile $(18.70-399)$ & 23 & 64.9 & $2.59(1.76-3.81)$ & & $2.07(1.36-3.14)$ & \\
\hline 2nd tercile $(400-749)$ & 43 & 44.8 & $1.79(1.17-2.72)$ & & $1.59(1.03-2.46)$ & \\
\hline 3rd tercile $(750-5000)$ & 61 & 25.0 & 1.00 & & 1.00 & \\
\hline
\end{tabular}

*Prevalence of $\mathrm{Fl}$ in the categories of the variables - percentage in line.**Wald test by means of Robust Poisson Regression. ***Based on the minimum wage of $2016=\mathrm{R} \$ 880.00$.

a: adjusted for demographic variables (age group and race/color); b: adjusted for demographic variables (age and color/race) and socioeconomic (paid work, Bolsa Família, schooling, and income). PR altered to $p<0.25$ in the adjusted analysis. The $p$-values in bold were

Qre 1534.30 (quote held on 12/31/2016 by the Central Bank of Brazil R\$3.2588) 
Table 3

concluded

Prevalence of food insecurity according to demographic and socioeconomic characteristics, obstetric and anthropometric background of pregnant women in Family Health Unities (FHU). Colombo, Paraná, 2016. $(n=316)$

\begin{tabular}{|c|c|c|c|c|c|c|}
\hline \multirow[t]{2}{*}{ Variables } & \multicolumn{2}{|c|}{$\mathrm{Fl}^{*}$} & \multirow[t]{2}{*}{ PR gross (Cl95\%) } & \multirow[t]{2}{*}{$p^{* *}$} & \multirow[t]{2}{*}{ Adjusted PR (C195\%) } & \multirow[t]{2}{*}{$p^{* *}$} \\
\hline & $\mathrm{n}$ & $\%$ & & & & \\
\hline \multicolumn{7}{|l|}{ Obstetric } \\
\hline No. of pregnancies & & & & $<0.001$ & & - \\
\hline One & 30 & 29.2 & 1.00 & - & - & \\
\hline Two & 90 & 45.1 & $1.54(1.06-2.24)$ & - & - & \\
\hline Three or more & 22 & 59.4 & $2.03(1.43-2.89)$ & & - & \\
\hline \multicolumn{7}{|l|}{ Anthropometric } \\
\hline Nutritional status during pregnancy & & & & 0.828 & & - \\
\hline Low weight & 13 & 35.1 & 1.00 & - & - & \\
\hline Eutrophy & 66 & 52.4 & $1.49(0.93-2.38)$ & - & - & \\
\hline Overweight & 35 & 37.6 & $1.07(0.64-1.78)$ & - & - & \\
\hline Obesity & 24 & 51.1 & $1.45(0.86-2.44)$ & - & - & \\
\hline
\end{tabular}

*Prevalence of $\mathrm{Fl}$ in the categories of the variables - percentage in line. $*$ Wald test by means of Robust Poisson Regression. ***Based on the minimum wage of $2016=\mathrm{R} \$ 880.00$

a: adjusted for demographic variables (age group and race/color); b: adjusted for demographic variables (age and color/race) and socioeconomic (paid work, Bolsa Família, schooling, and income). PR altered to $p<0.25$ in the adjusted analysis. The $p$-values in bold were statistically significant $(p<0.05)$.

FI: Food Insecurity; PR: Prevalence Ratio; C195\%: Confidence Interval of $95 \%$.

Quantity of information ignored by the variable: age $\mathrm{n}=1$; color/race, $\mathrm{n}=4$; paid work $\mathrm{n}=1$; Bolsa Familia Program $\mathrm{n}=1$; schooling $\mathrm{n}=1$, household in come per capita $\mathrm{n}=34$; Number of pregnancies $n=1$; nutritional status $n=13$; food insecurity, $n=1$. Household income per capita in US Dollars: 1 st tercile $\$ 5.74$ per-122.44; 2nd tercile $\$ 122.74-229.84 ; 3$ rd tercile $\$ 230.15$ -

1534.30 (quote held on 12/31/2016 by the Central Bank of Brazil R $\$ 3.2588$ ) 


\section{Discussion}

FI is a global public health issue and is one of the effects of poverty and social inequalities. Almost half of the pregnant women evaluated in this study were in a situation of FI - a prevalence similar to that observed in pregnant women assisted by the primary health care system in the city of Maceió, in the northeastern Brazilian state of Alagoas, in 2014.9 Brazil's National Survey on Demography and Health of Children and Women (PNDS), ${ }^{17}$ carried out in 2006, described the profile of the female population of childbearing age and children under five years old and identified the health and nutrition situation of 12,645 households. PNDS identified the occurrence of FI in $37.5 \%$ of households in the country and $15 \%$ of households in the Southern Region. Among the pregnant women participating in this study, the prevalence of FI (45.1\%) was three times higher than that estimated by the PNDS for households with women from Southern Brazil (15\%), 17 which reinforces the risk situation in the evaluated group.

We identified a higher prevalence of FI among pregnant women aged 30 years or more, compared to those with age of 19 years or less. A similar result (46.7\%) was found in a study carried out in 2014 with pregnant women from the Brazilian northeast. 9 Pregnant women aged 30 years old or more may have a higher number of children, thus increasing the chances of having other children living in the household (including children under the age of 18). The Brazilian National Household Sample Survey (PNAD) 5 of 2013 found the lowest prevalence of FI in households with no residents under 18 years of age $(16.6 \%)$, when compared to households with children under 18 years old $(28.8 \%)$.

Pregnant women of black or indigenous color/race presented higher prevalence of FI when compared to those of white or Asian features. The PNAD $^{5}$ survey of 2009 and 2013 showed that people of black race presented higher rates of prevalence of FI. When evaluating populations by color or race, the PNAD 2013 found FI of $17.2 \%$ among white people, $33.4 \%$ among black people, and $28.0 \%$ among Asian and indigenous peoples. Women of black color/race present a persistently unfavorable situation in different life and health indicators, such as: higher rates of teenage pregnancy, low schooling, unpaid occupations, and not having a partner. ${ }^{18}$

Pregnant women with lower per capita income had a higher prevalence of FI. Studies have pointed to insufficient household income and low level of education as factors associated with FI.4,9,10,19-22 Oliveira et al. 9 found $44.9 \%$ of pregnant women with a household income that is less than the minimum wage in the situation of FI. Panigassi et $a l .{ }^{20}$ pointed out that households with incomes of up to two minimum wages presented higher odds ratios for presenting FI, ranging from 2.94 to 12.95 .

Higher schooling increases opportunities for access to formal or higher income jobs, which improves the conditions that promote food security.4,9,10,19-22 Although they have more years of study than men, women receive lower wages, since they find a labor market filled with gender differences. Moreover, they are more susceptible to informal ties of work or to unemployment, ${ }^{22}$ conditions that favor FI.

A systematic review pointed out to the relationship between FI and obesity, 23 an association not found among the pregnant women evaluated in the present study. Despite this, the high prevalence of FI and overweight among women is striking. In contexts characterized by a nutritional transition process, such as Brazil's, the coexistence of conditions related to food excess and deficiency is common. ${ }^{24} \mathrm{FI}$ can lead to the worsening of not only the quantity but also of the quality of the food consumed, which may favor an increase in body weight. In a study of low-income women participating in a care program in the United States, it was observed that FI was inversely associated with food quality. 25

Among the limitations of the present study is the fact that the sample is composed only by pregnant women who use a public health unit, which excludes private health services. This may have reduced the socioeconomic heterogeneity of the sample, favoring and increasing the prevalence of FI.

Among the variables presented, the number of respondents to the questions about income was lower than that defined for the minimum sample of the study. Nevertheless, the study had the power of identifying inequalities in prevalence of FI according to the socioeconomic conditions of the pregnant women that were evaluated. We may also mention the cross-sectional design of the study among its limitations, since it does not allow the inference of cause-and-effect relationships. It is noteworthy the use of the short version of the Brazilian Household Food Insecurity Measurement Scale (EBIA) for FI identification, which allows evaluating the presence or absence of FI, but does not measure its FI degree. This version also identifies only the FI for each individual, not including other residents of the household. On the other hand, the short version of EBIA has the advantage of reducing the time of application of the questionnaire, especially in researches with 
other outcomes and exposures, and helps to minimize participant fatigue without impairing the validity indexes and the fidelity verified in the original scale. 15

The concept of FI is complex and involves other aspects related to access to food and other goods and services. Thus, future research will be capable of investigating in depth aspects related to FI among pregnant women and their determinants, as well as evaluating its nutritional dimension.

Finally, the importance of the early identification of women that are most vulnerable to FI is highlighted, in order to minimize the negative repercussions of this condition during pregnancy, enabling the full development of the concept. Therefore, it is necessary to refer these pregnant women to social programs of income transfer and other social facilities that aim at reducing social inequalities.

Promoting access to low-cost, nutritionally

\section{References}

1. Food and Agriculture Organization of the United Nations.Direito à Alimentação e Segurança Alimentar e Nutricional nos Países da CPLP. Diagnóstico de Base. Roma: FAO; 2011

2. Bickel, G, Nord M, Price C, Hamilton W, Cook J Measuring food security in the United States: Guide to measuring household food security. Office of Analysis, Nutrition and Evaluation, USA: USDA; 2000.

3. Food and Agriculture Organization of the United Nations Cúpula Mundial de Alimentação (Declaração de Roma Sobre a Segurança Alimentar Mundial \& Plano de Ação da Cúpula Mundial da Alimentação). World Summit Food. Roma: FAO; 1996.

4. Santos FDS. Elas têm fome de quê? (In)segurança alimentar e condições de saúde e nutrição de mulheres na fase gestacional [Tese]. Salvador: Instituto de Saúde Coletiva da Universidade Federal Bahia; 2015.

5. IBGE (Instituto Brasileiro de Geografia e Estatística). Pesquisa Nacional por amostra de domicílios: síntese de indicadores 2013. IBGE; 2015

6. Whitaker RC, Phillips SM, Orzol SM. Food insecurity and the risks of depression and anxiety in mothers and behavior problems in their preschool-aged children. Pediatrics 2006; 188 (3): 859-68

7. Martins Sobrinho F, Silva YC, Abreu MNS, Pereira SCL, Dias Júnior CS. Fatores Determinantes da Insegurança Alimentar e Nutricional: Estudo Realizado Em Restaurantes Populares de Belo Horizonte, Minas Gerais, Brasil. Ciên Saúde Coletiva. 2014; 19 (5): 1601-11.

8. Marano D, Gama SGN, Domingues RMSM, Souza Júnior PRB. Prevalência e fatores associados aos desvios nutricionais em mulheres na fase pré-gestacional em dois municípios do Estado do Rio de Janeiro, Brasil. Rev Bras Epidemiol. 2014; 17 (1): 45-58. adequate and safe food (without compromising access to other essentials to life) is paramount in promoting food security. Investments in actions that provide an increase in schooling in a timely manner, as well as policies that increase female insertion and permanence in formal labor market can influence the reduction of FI among this vulnerable group.

\section{Acknowledgments}

The authors would like to thank the Academic Publishing Advisory Center (Centro de Assessoria de Publicação Acadêmica, CAPA www.capa.ufpr.br) of the Federal University of Paraná for assistance with English language editing. This study was financed in part by the Coordenação de Aperfeiçoamento de Pessoal de Nível Superior Brasil (CAPES) - Finance Code 00.1, through the Programa de Apoio à Pós-Graduação (PROAP).

9. Oliveira ACM, Tavares MCM, Bezerra AR. Insegurança alimentar em gestantes da rede pública de saúde de uma capital do nordeste brasileiro. Ciênc Saúde Coletiva. 2017; 22 (2): 519-26.

10. Oliveira ACM, Barros AMR, Ferreira RC. Fatores de associados à anemia em gestantes da rede pública de saúde de uma capital do Nordeste do Brasil. Rev Bras Ginecol Obstet. 2015; 37 (11): 505-11.

11. Tourinho AB, Reis LBSM. Peso ao Nascer: Uma Abordagem Nutricional. Com. Ciênc Saúde. 2012; 23 (1): 19-30.

12. IPARDES (Instituto Paranaense de Desenvolvimento Econômico e Social). Caderno Estatístico Município de Colombo. Curitiba: IPARDES; 2016. Disponível em: $<$ http://www.ipardes.gov.br/cadernos/MontaCadPdf1.php? Municipio $=83400 \& b t O k=o k>$

13. Atalah E, Castillo C, Castro R, Aldea A. Propuesta de un nuevo estándar de evaluación nutricional en embarazadas. Rev Med Chile. 1997; 125: 1429-36.

14. Santos LP. Proposta de versão curta da Escala Brasileira de Insegurança Alimentar. Rev Saúde Pública. 2014; 48 (5): 783-89.

15. Pérez-Escamilla R, Segall-Corrêa AM, Maranha LK, Sampaio MFA, Marin-León L, Panigassi G. An adapted version of the U.S. Department of Agriculture Food Insecurity module is a valid tool for assessing household food insecurity in Campinas, Brazil. J Nutr. 2004; 134 (8): 1923-8.

16. StataCorp. 2011. Stata Statistical Software: Release 12. College Station, TX: StataCorp LP.

17. Brasil. Ministério da Saúde. Pesquisa Nacional de Demografia e Saúde da Criança e da Mulher - PNDS 2006: dimensões do processo reprodutivo e da saúde da criança. Brasília, DF; 2009. 
18. Leal MC, Gama SGN, Cunha CB. Desigualdades raciais, sociodemográficas e na assistência ao pré-natal e ao parto 1999-2001. Rev Saúde Pública. 2005; 39 (1):100-7.

19. Salles-Costa R, Pereira RA, Vasconcellos MTL, Veiga VMRM, Jardim BC. Associação entre fatores socioeconômicos e insegurança alimentar: estudo de base populacional na Região Metropolitana do Rio de Janeiro, Brasil. Rev Nutr Campinas. 2008; 21: 99-109.

20. Panigassi G, Segall-Corrêa AM, Marin-León L, PérezEscamilla R, Sampaio MFA, Maranha LK. Insegurança alimentar como indicador de iniquidade: análise de inquérito populacional. Cad Saúde Pública. 2008; 24 (10): 2376-84.

21. Diniz CSG, d'Orsi E, Domingues RMSM, Torres JA, Dias MAB, Schneck CA, Lansky S, Teixeira NZF, Rance S, Sandall J. Implementação da presença de acompanhantes durante a internação para o parto: dados da pesquisa nacional nascer no Brasil. Cad Saúde Pública. 2014; 30 : 140-53.

Received on July 19, 2017

Final version presented on May 15, 2018

Approved on July 19, 2018
22. Silva EM; Campelo AK. Efeito do número de filhos na distribuição condicional da renda familiar. Uma aplicação de variáveis instrumentais para estimar o efeito quantilíco de um tratamento [Dissertação]. Recife: Universidade Federal de Pernambuco; 2003.

23. Franklin BJA, Love D, Puckett S, Macklin J, White-Means S. Exploring Mediators of Food Insecurity and Obesity: A Review of Recent Literature. J Comm Health. 2011; 37 (1): 253-64

24. Coutinho JG, Gentil PC, Toral N. A desnutrição e obesidade no Brasil: o enfrentamento com base na agenda única da nutrição. Cad SaúdePública.2008; 24 (Supl. 2): 332S-40S.

25. Sanjeevi N, Freeland-Graves J, Hersh M. Food insecurity, diet quality and body mass index of women participating in the Supplemental Nutrition Assistance Program: The role of intrapersonal, home environment, community and social factors. Appetite. 2018; 125: 109-17 